\title{
2013 Korean Society of Hypertension guidelines for the management of hypertension. Part II- treatments of hypertension
}

\author{
Jinho Shin ${ }^{1}$, Jeong Bae Park², Kwang-il Kim³, Ju Han Kim, Dong Heon Yang ${ }^{5}$, Wook Bum Pyun ${ }^{6}$, \\ Young Gweon Kim ${ }^{7}$ Gheun-Ho Kim ${ }^{1}$, Shung Chull Chae ${ }^{5^{*}}$ and The Guideline Committee of the Korean Society of \\ Hypertension
}

This article is 2/3, Please see related article 10.1186/s40885-014-0014-1.

\begin{abstract}
Treatment strategies are provided in accordance with the level of global cardiovascular risk, from lifestyle modification in the lower risk group to more comprehensive treatment in the higher risk group. Considering the common trend of combination drug regimen, the choice of the first drug is suggested more liberally according to the physician's discretion.
\end{abstract}

Keywords: Antihypertensive treatment, Cardiovascular risk, Guidelines, Hypertension, Lifestyle, Organ damage

\section{Treatments of hypertension}

The purpose of hypertension (HTN) treatment is to prevent cardiovascular disease (CVD) caused by increased blood pressure (BP) and decrease mortality by controlling high BP. In patients who already have established CVD, treatment aims to control BP to prevent progression or recurrence of disease in order to decrease mortality and improve quality of life. HTN treatment provides greater benefit in patients who are at higher risk for CVD. Most clinical studies of HTN have found that lowering systolic blood pressure (SBP) by approximately 10 to $20 \mathrm{~mm} \mathrm{Hg}$ or diastolic blood pressure (DBP) by approximately 5 to $10 \mathrm{~mm} \mathrm{Hg}$ can reduce the occurrence of stroke by $30 \%$ to $40 \%$ and that of ischemic heart disease by $15 \%$ to $20 \%$ [1]. Because most clinical studies were performed over a relatively short period, the benefits of HTN treatment over a period of 5 years or more seem to be much more pronounced than the treatment efficacy observed in clinical studies. The benefits of HTN treatment are not affected by sex or age and

\footnotetext{
* Correspondence: scchae@knu.ac.kr

${ }^{5}$ Division of Cardiology, Department of Internal Medicine, Kyungpook National University School of Medicine, 130 Dongdeok-ro, 700-721 Jung-gu, Daegu, Korea

Full list of author information is available at the end of the article
}

are also similar for the treatment of systolic HTN in the elderly. HTN treatment was found to be the most costeffective intervention for prevention of CVD.

\section{Strategy for hypertension treatment}

If a patient is already known to have high BP, the diagnosis of HTN must be confirmed prior to treatment by measuring the out-of-clinic BP, such as at home or using 24-h monitoring. Measurement of out-of-clinic BP helps not only to obtain a more accurate diagnosis but also to determine the appropriate treatment for the patient and to increase treatment compliance. If HTN is diagnosed, the risk factors for CVD, associated diseases, and existence of hypertensive complications should be investigated (Figure 1). Patients with white coat HTN, which is defined as high BP in but not out of the clinic, must be followed up periodically at 3- to 6-month intervals because their risk of CVD increases over time. HTN treatment must include nondrug therapy (such as lifestyle modification) concomitant with drug therapy. The initiation of drug therapy needs to be considered and determined on the basis of not only the BP level but also the presence of risk factors for CVD and evidence of damage to target organs. Drug therapy may be used in patients with a BP of $140 / 90 \mathrm{~mm} \mathrm{Hg}$ or higher regardless of the 


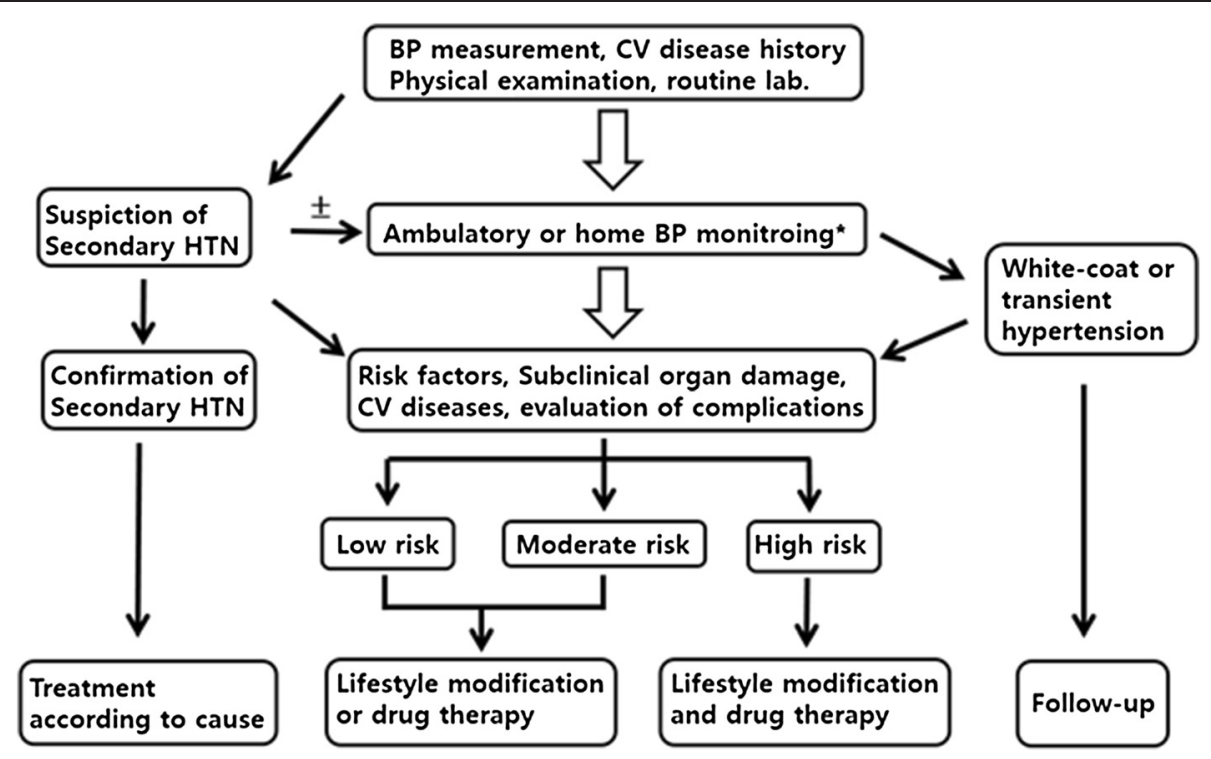

Figure 1 Treatment strategies for hypertension. BP blood pressure; CV cardiovascular; HTN hypertension. \pm Optional. ${ }^{*}$ Recommended test. ${ }^{\dagger}$ In the moderate to high risk group, drug therapy can be considered for stage 2 hypertension patients.

existence of other risk factors or associated diseases. The quality of life of patients with HTN can be affected by physical and psychological problems caused by HTN, the main and side effects of the drug, and the relationship between the patient and physician. Adequate communication and provision of information can decrease the dosage and frequency of medication used, which increases patient compliance, improves the BP control rate, and promotes continuous treatment.

\section{Initiation of hypertension treatment}

Prehypertension stage II

Cardiovascular (CV) mortality caused by HTN increases twofold for each $20-\mathrm{mm} \mathrm{Hg}$ increase in SBP or $10-\mathrm{mm}$ $\mathrm{Hg}$ increase in DBP over the baseline level of 115/ $75 \mathrm{~mm} \mathrm{Hg}[1,2]$. Therefore, in patients with BP over $120 / 80 \mathrm{~mm} \mathrm{Hg}$, nondrug therapy is recommended to prevent the occurrence of HTN and CV events. Initiation of drug therapy in patients with stage 2 prehypertension can delay the progression to HTN $[3,4]$, but there is little evidence for the effectiveness of early intervention in most clinical studies [5]. Initiation of drug therapy during stage 2 prehypertension showed no consistent benefit in patients with prediabetes [6,7], DM [8], stroke [9], or coronary artery disease; [10] therefore, the cost-benefit ratio should be considered in the decision to use drug therapy (Table 1).

\section{Hypertension stage I}

Patients with stage 1 HTN without other risk factors are in the low-risk group and would not be expected to obtain a greater benefit from treatment [11]. However, their overall risk will increase over time, and the window in which treatment could reverse progression might be

Table 1 Treatment for hypertension according to the risk

\begin{tabular}{|c|c|c|c|}
\hline \multirow[t]{2}{*}{ Risk factor } & \multicolumn{3}{|l|}{ Blood pressure $(\mathrm{mm} \mathrm{Hg})$} \\
\hline & $\begin{array}{l}\text { Stage } 2 \text { prehypertension } \\
(130-139 / 85-89)\end{array}$ & $\begin{array}{l}\text { Stage } 1 \text { hypertension } \\
(140-159 / 90-99)\end{array}$ & $\begin{array}{l}\text { Stage } 2 \text { hypertension } \\
(\geq 160 / 100)\end{array}$ \\
\hline Risk factors 0 & Lifestyle modification & $\begin{array}{l}\text { Lifestyle modification }{ }^{\text {a }} \\
\text { or drug therapy }\end{array}$ & $\begin{array}{l}\text { Lifestyle modification } \\
\text { or drug therapy }\end{array}$ \\
\hline Risk factors $1-2$ other than DM & Lifestyle modification & $\begin{array}{l}\text { Lifestyle modification }{ }^{\text {a }} \\
\text { or drug therapy }\end{array}$ & $\begin{array}{l}\text { Lifestyle modification } \\
\text { and drug therapy }\end{array}$ \\
\hline Risk factors $\geq 3$, subclinical organ damage & Lifestyle modification & $\begin{array}{l}\text { Lifestyle modification } \\
\text { and drug therapy }\end{array}$ & $\begin{array}{l}\text { Lifestyle modification } \\
\text { and drug therapy }\end{array}$ \\
\hline DM, cardiovascular disease, chronic kidney disease & Lifestyle modification or drug therapy ${ }^{b}$ & $\begin{array}{l}\text { Lifestyle modification } \\
\text { and drug therapy }\end{array}$ & $\begin{array}{l}\text { Lifestyle modification } \\
\text { and drug therapy }\end{array}$ \\
\hline
\end{tabular}

DM diabetic mellitus.

${ }^{a}$ Lifestyle modification is carried within several weeks to 3 months. ${ }^{\dagger}$ Drug therapy may be begun immediately according to the height of BPs.

${ }^{b}$ Drug therapy may be begun as target blood pressure determined. 
missed. Modern drugs are generally inexpensive and safe, and drug therapy has been found to be costeffective given that patients generally fail to accomplish lifestyle changes. Drug therapy is recommended only after measurement of the out-of-clinic BP in order to exclude the possibility of white coat HTN $[12,13]$. The effect of medical therapy on white coat HTN has not yet been proven; however, as white coat HTN poses increased metabolic risk and risk for $\mathrm{CV}$ events over the long term, lifestyle modification is recommended at first, and patients should be observed periodically for development of persistent HTN. Drug therapy should be instituted immediately in patients with high-risk stage I HTN $[14,15]$.

\section{Hypertension stage II}

According to most randomized clinical trials, immediate drug therapy is warranted in patients with a BP of $\geq 160$ / $100 \mathrm{~mm} \mathrm{Hg}$ due to the noticeable effect of treatment $[5,14,15]$.

\section{Hypertension in the elderly}

The effect of drug therapy against HTN is clear irrespective of age [16]. Drug therapy can be initiated in elderly patients when the SBP is $160 \mathrm{~mm} \mathrm{Hg}$ or higher; consistent drug therapy can be considered if the SBP is 140 to $159 \mathrm{~mm} \mathrm{Hg}$ and the patient tolerates the drug well.

\section{Target blood pressure in the treatment of hypertension}

As shown in Table 2, except under specific circumstances, the target BP is generally an SBP of less than $140 \mathrm{~mm} \mathrm{Hg}$ and a DBP of less than $90 \mathrm{~mm} \mathrm{Hg}[5,17,18]$.

\section{Hypertension in the elderly}

The effects of decreasing BP in elderly patients with HTN are clear, but it is difficult to lower BP to less than $140 \mathrm{~mm} \mathrm{Hg}$ in such patients [19], and there is no difference in prognosis between BP targets of 140 and $150 \mathrm{~mm}$

Table 2 Target blood pressures in hypertension treatment

\begin{tabular}{lll}
\hline Situations & $\begin{array}{l}\text { Systolic blood } \\
\text { pressure }(\mathbf{m m ~ H g})\end{array}$ & $\begin{array}{l}\text { Diastolic blood } \\
\text { pressure }(\mathbf{m m ~ H g})\end{array}$ \\
\hline Uncomplicated hypertension & 140 & 90 \\
Elderly & $140-150$ & 90 \\
Diabetes mellitus & 140 & 85 \\
Stroke & 140 & 90 \\
Coronary artery disease & 140 & 90 \\
Chronic kidney disease & & \\
$\quad$ Without albuminuria & \\
$\quad$ With albuminuria & 140 & 90 \\
\hline
\end{tabular}

${ }^{\mathrm{a}}$ Microalbuminuria or macroalbuminuria.
Hg. Therefore, the target SBP is approximately 140 to $150 \mathrm{~mm} \mathrm{Hg}$ with a DBP that is not excessively low, i.e., less than approximately $60 \mathrm{~mm} \mathrm{Hg}[20,21]$.

\section{Hypertension in patients with diabetes}

Reduction of BP in patients with HTN and diabetes is very important for reducing CV complications [22]. Few studies have shown reduction of SBP to below $130 \mathrm{~mm}$ $\mathrm{Hg}$. Even reduction of SBP to less than $120 \mathrm{~mm} \mathrm{Hg}$ did not demonstrate any additional preventive effect on CVD but rather showed a deleterious effect on renal function; therefore, the recommended target $\mathrm{BP}$ is an SBP below $140 \mathrm{~mm} \mathrm{Hg}$ [23] and a DBP below $85 \mathrm{~mm}$ $\mathrm{Hg}$ [24].

\section{Hypertension in patients with stroke}

HTN is a most important causative risk factor for stroke. HTN treatment can reduce the recurrence of stroke and CV events [25-27], but there are no distinct benefits from reducing SBP to below $130 \mathrm{~mm} \mathrm{Hg}$ [28]. In particular, a recent clinical study in patients with cerebral infarction showed no additional benefit from controlling SBP below $140 \mathrm{~mm} \mathrm{Hg}$ [29]. Considering the clinical studies to date, a target SBP below $140 \mathrm{~mm} \mathrm{Hg}$ is recommended in patients with stroke.

\section{Hypertension in patients with coronary artery disease}

Reduction of SBP to below $130 \mathrm{mmHg}$ shows no consistent prevention of CVD in patients with HTN and coronary artery disease [30-32]. Therefore, a target SBP of below $140 \mathrm{~mm} \mathrm{Hg}$ is recommended.

\section{Hypertension in patients with chronic kidney disease}

The major purpose of controlling BP in patients with chronic kidney disease (CKD) is to prevent deterioration of renal function and reduce the occurrence of CVD. Further control of SBP to below $140 \mathrm{~mm} \mathrm{Hg}$ has shown no additional benefit in patients with HTN and CKD without diabetes [33-35]. However, the data on the goal of treatment in patients with HTN and CKD with diabetes is even more insufficient [36,37]. Meta-analysis has not proven that a target $\mathrm{BP}$ of less than $140 \mathrm{~mm} \mathrm{Hg}$ is any more effective at preventing cardiac and renal events $[23,38,39]$. Therefore, on the basis of recent clinical data, a target SBP of less than $140 \mathrm{~mm} \mathrm{Hg}$ is recommended regardless of the presence of diabetes. However, a target SBP below $130 \mathrm{~mm} \mathrm{Hg}$ can be recommended in patients with HTN with prominent albuminuria [40].

\section{Low threshold of hypertension treatment}

As BP increases, the CV risk also increases, whereas as $\mathrm{BP}$ decreases, the risk of the occurrence of a $\mathrm{CV}$ event decreases to some extent. There is insufficient clinical data to prove the J-curve hypothesis (a hypothesis that 
excessive lowering of SBP and DBP will increase rather than decrease $\mathrm{CV}$ events and mortality), but post hoc analysis of clinical studies suggests the possibility of such a J-curve effect and a pathophysiological detriment of excessively low BP [41]. Therefore, it is not recommended to target BP too low, but additional studies are needed to determine how low a BP is desirable.

\section{Nondrug therapy and lifestyle modification}

Nondrug therapy or lifestyle modification, such as adoption of a healthy diet, increasing exercise, smoking cessation, and moderation of alcohol intake, has shown great ability to lower BP and is important in all patients with HTN. Even in patients with prehypertension, nondrug therapy is strongly recommended to prevent progression to HTN (Table 3). Healthy lifestyle habits have almost the same BP-decreasing effect as approximately one dose of anti-HTN drug [42]. Furthermore, in patients with HTN who are using medication, adding lifestyle modification can reduce the dose and frequency of medication used, maximize the effect of the drug, and reduce side effects. Lifestyle improvement also has other beneficial effects on CV risk in addition to the lowering of BP. Clinicians should remain aware that it is difficult to maintain lifestyle modifications long-term or to achieve a target BP for the HTN in stage II or higher even at best. Therefore, the clinician should provide encouragement to continue lifestyle modifications while also educating the patient in their limitations. In addition, because adopting several types of lifestyle modification rather than one alone maximizes the effects, a simultaneous approach is recommended to meet the goal of minimizing CVD.

\section{Restriction of salt intake}

According to the 2010 KNHANES data, it is estimated that Korean consume $12.2 \mathrm{~g}$ ( $4.9 \mathrm{~g}$ sodium) of salt daily,

\begin{tabular}{|c|c|c|}
\hline $\begin{array}{l}\text { Lifestyle } \\
\text { modification }\end{array}$ & $\begin{array}{l}\text { BP reduction (systolic/ } \\
\text { diastolic BP, } \mathrm{mm} \mathrm{Hg} \text { ) }\end{array}$ & Recommendation \\
\hline $\begin{array}{l}\text { Restriction of } \\
\text { salt intake }\end{array}$ & $-5.1 /-2.7$ & $\begin{array}{l}\text { Less than } 6 \mathrm{~g} \text { of salt per } \\
\text { day }\end{array}$ \\
\hline $\begin{array}{l}\text { Body weight } \\
\text { reduction }\end{array}$ & $-1.1 /-0.9$ & Each reduction of $1 \mathrm{~kg}$ \\
\hline $\begin{array}{l}\text { Moderation in } \\
\text { drink }\end{array}$ & $-3.9 /-2.4$ & $\begin{array}{l}\text { Less than two glasses per } \\
\text { day }\end{array}$ \\
\hline Exercise & $-4.9 /-3.7$ & $\begin{array}{l}\text { 30-50 min per day for } \\
\text { more than } 5 \text { days in a week }\end{array}$ \\
\hline Diet control & $-11.4 /-5.5$ & $\begin{array}{l}\text { Vegetables-based healthy } \\
\text { diet habit }\end{array}$ \\
\hline
\end{tabular}

$B P$ blood pressure. which is a higher amount than western (10 g) or Japanese $(10.7 \mathrm{~g})$ populations [43]. Salt intake can increase the risk for $\mathrm{CV}$ events because of the association of central hemodynamics with the estimated 24-h urinary sodium in patients with HTN [44]. Halving the daily salt intake of $10.5 \mathrm{~g}$ will decrease SBP by 4 to $6 \mathrm{~mm} \mathrm{Hg}$ $[45,46]$. However, there have been variable and confusing reports about the relationship between salt restriction and CV events [47-50]. Despite the absence of randomized large-scale trials, some reports of a J-curve phenomenon for salt intake and CV events, and lack of Korean data, there is no clear evidence that salt restriction is harmful, especially among Koreans with their high-salt intake. Therefore, we must recommend decreasing salt intake in accordance with other guidelines [51].

The daily recommended amount of salt is less than $6 \mathrm{~g}$ (sodium $[\mathrm{g}] \times 2.5$ ). Salt reduction has many benefits, including lowering of $\mathrm{BP}$ and reducing the need for diuretics, which cause detrimental urinary loss of potassium and calcium. The avoidance of urinary calcium loss prevents the development of osteoporosis and renal calculi.

Sensitivity to salt tends to be higher in patients who are elderly, obese, or have diabetes or family members with HTN. Greater salt sensitivity means a greater reduction in BP in response to salt restriction. The dietary habits must be modified. Some recommendations are not to put additional salt on the table during the meal and to avoid high-salt processed foodstuffs. Some frequently eaten foods, such as kimchi, stew, soup, salted fermented seafood, instant ramen, and dry bar snacks containing meat and fish, are very salty. When cooking foods, natural ingredients should be used instead of synthetic flavoring agents. The patient should not only reduce absolute salt intake but also try to consume more low-salt foods.

\section{Weight reduction}

HTN is closely related to obesity, and weight reduction decreases BP. Central obesity in particular is closely associated with HTN, dyslipidemia, diabetes, and CV death. In a patient heavier than $110 \%$ of ideal body weight, weight reduction of only $5 \mathrm{~kg}$ can decrease BP. The beneficial effects of weight reduction are higher in patients with diabetes, dyslipidemia, and left ventricular hypertrophy (LVH). The combination of weight reduction with exercise, moderation of alcohol consumption, and reduction of salt intake has synergistic effects on BP. The recommended initial goal of weight reduction is 4 to $5 \mathrm{~kg}$, with an additional $5 \mathrm{~kg}$ reduction after the initial goal has been achieved.

The ideal body mass index (BMI) (weight $[\mathrm{kg}] /$ height $[\mathrm{m}]^{2}$ ) varies among reports and according to nationality. A collaborative analysis reported that BMI either above or below the apparent optimum of approximately 22.5 to $25 \mathrm{~kg} / \mathrm{m}^{2}$ is itself a strong predictor of overall mortality 
[52]. Another meta-analysis found that both overweight and grade 1 obesity were associated with significantly lower all-cause mortality [53]. A report on data from 1.2 million Koreans revealed that the risk of death from any cause was lowest among patients with a BMI of 23.0 to $24.9 \mathrm{~kg} / \mathrm{m}^{2}$ and recommended a BMI of less than $25 \mathrm{~kg} /$ $\mathrm{m}^{2}$ [54]. Unfortunately, there are no Korean-specific data on appropriate waist circumference. A waist circumference of less than $90 \mathrm{~cm}$ for men and $80 \mathrm{~cm}$ for women is recommended for Asian individuals [55].

The recommendations for weight reduction are to eat breakfast every morning, eat slowly, and avoid a highcarbohydrate diet, alcohol, snacks such as bread and cookies, and sweetened beverages. A high-fiber diet is recommended, and a high-fat diet including food fried with oil is prohibited. Patients should try to eat as many fruits and vegetables as possible and to avoid meals containing large amounts of cholesterol and saturated fatty acids.

\section{Moderation of alcohol consumption}

$\mathrm{BP}$ tends to increase in patients who drink excessive amounts of alcohol, and such patients are also resistant to antihypertensive drugs. An appropriate moderate daily amount of alcohol is less than 20 to $30 \mathrm{~g}$ for men or 10 to $20 \mathrm{~g}$ for women. A man or woman with lowerthan-average body weight is more sensitive to alcohol and is therefore permitted half of the recommended amount. Heavy drinkers should be warned that they are high risk for stroke. One bottle of beer $(720 \mathrm{~mL})$, one glass of wine (range, 200 to $300 \mathrm{~mL}$ ), one glass of sake $(200 \mathrm{~mL})$, two shots of whisky $(60 \mathrm{~mL})$, or two to three glasses of soju corresponds to $30 \mathrm{~g}$ of alcohol.

\section{Exercise}

The benefits of regular exercise are lowering of BP, improvement of cardiopulmonary function, reduction of body weight, improvement of the lipid profile (including elevation of HDL cholesterol), and reduction of emotional stress. Aerobic exercises such as brisk walking, jogging, bicycling, swimming, jumping rope, playing tennis, and aerobic dancing are recommended for patients with HTN. The appropriate intensity of exercise is $60 \%$ to $80 \%$ of the maximal heart rate (220-age in years). Such exercise should be performed five to seven times per week. Aerobic exercise should begin at low intensity for 10 to $20 \mathrm{~min}$ and then increase to appropriate intensity for another 30 to $60 \mathrm{~min}$. Every exercise session should start with $5 \mathrm{~min}$ of warm-up exercise and end with $5 \mathrm{~min}$ of cool-down exercise. In addition to aerobic exercise, isometric exercise such as weight lifting can reduce BP, produce metabolic benefits, and increase muscle power. Isometric exercise is recommended two to three times per week [56]. Isotonic exercise such as lifting a heavy object (anaerobic metabolism) can increase BP and may be dangerous in patients with poorly controlled HTN. Most patients with uncomplicated HTN can begin regular exercise without an initial evaluation and increase the duration and intensity to appropriate levels as possible. However, patients with known CVDs or other risk factors are recommended to start the exercise only after complete evaluation by an exercise consultant and to follow a program.

\section{Smoking cessation}

During smoking, the BP increases temporarily in response to nicotine. Among patients with white coat HTN, smokers maintain a higher daytime ambulatory SBP than do nonsmokers with a similar office BP [57]. Smoking, like HTN, is a powerful risk factor for CVD [58], and CV events are inevitable in patients who continue smoking regardless of BP control. Second-hand smoking is also harmful. Smoking cessation should be advised at every opportunity. Lownicotine-containing replacement materials do not increase $\mathrm{BP}$ and can be recommended in combination with behavior therapy. During smoking cessation, regular exercise and diet therapy should be emphasized in order to prevent weight gain.

\section{Healthy diet management}

$\mathrm{BP}$ is lower in vegetarians than in people who mainly eat meat, and maintaining a vegetarian diet can reduce BP. The BP-lowering effect results not from decreasing the intake of animal protein but from increasing the intake of vegetables and fruits in combination with decreasing the intake of saturated fatty acids. In a study in elderly people, BP decreased by $3 / 1 \mathrm{~mm} \mathrm{Hg}$ when intake of vegetables and fruits was increased alone but by $6 / 3 \mathrm{mmHg}$ when it was combined with a decrease in fat intake [59-61]. In patients with HTN, a combined diet with greater intake of calcium, magnesium, and potassium decreased BP by an additional $11 / 6 \mathrm{~mm} \mathrm{Hg}[59,61,62]$. A regular diet composed mainly of fish reduces BP and improves the lipid profile in obese patients with HTN. The Dietary Approaches to Stop HTN (DASH) diet, which is rich in vegetables, fruits, and fish and low in fat, is recommended for patients with HTN [63].

\section{Others}

Caffeine from various foods rapidly increases BP, but the effect does not progress to HTN because tolerance to caffeine develops. Emotional stress increases both BP and the risk for CVD, making the control of emotional stress important for the management and patient compliance of HTN. Further studies are required to examine the long-term effects of stress control on HTN and CVD. The effectiveness of various methods of stress management, such as relaxation and biofeedback, for the 
management of HTN remains uncertain. There is still no clear evidence for the effects of micronutrients, calcium, magnesium, and supplementary fiber on BP.

\section{Pharmacological therapy}

The occurrence of CV events in patients with HTN can be decreased by reducing the BP. Currently available antihypertensive drugs are more effective than placebo for prevention of CVD. This preventive effect is relatively larger for stroke than for coronary artery disease. The extent to which $\mathrm{CV}$ events are reduced depends on the degree of BP reduction. All major classes of antihypertensive drugs, including beta-blockers and diuretics, are suitable for first-line treatment. However, the individual drug should be prescribed with consideration of the patient's individual situation, including age, comorbidities, and possible adverse effects. Simplifying the medication schedule, careful monitoring of the adverse effects, and checking the $\mathrm{BP}$ at home are useful for improving patient compliance and making the patient an active participant in the treatment.

\section{Strategies for prescription of antihypertensive drugs \\ Principles of drug selection}

For reduction of long-term CV morbidity and mortality, it is essential to control most of the modifiable risk factors and to reduce the BP to less than 140/90 $\mathrm{mm} \mathrm{Hg}$ [40]. Drug therapy is initiated at a low dose to avoid adverse effects. The preferred drugs are long-acting and can be taken only once a day [64]. Drugs with a high trough/peak ratio $(>0.5)$ are helpful for improving compliance and to maintain a stable BP with minimal variability [65]. If it is impossible to control BP with once-daily dosing, a twicedaily schedule is an alternative option. Angiotensinconverting enzyme (ACE) inhibitors, angiotensin receptor blockers (ARBs), calcium antagonists, beta-blockers, and diuretics are all suitable for initiation of antihypertensive treatment. The indications, contraindications, comorbidities, and presence of asymptomatic organ damage should all be considered in the choice of drug (Table 4). There is no uniform consensus on the role of beta-blockers in elderly patients with HTN, so prescription of beta-blockers in the elderly should be limited to special circumstances. Beta-blockers should also be used with care in patients at high risk for diabetes because in combination with diuretics they can increase the risk of new onset of diabetes [40]. In patients with BP higher than 160/100 mm Hg or more than $20 / 10 \mathrm{~mm} \mathrm{Hg}$ above the target BP, two drugs can be prescribed in combination to maximize the antihypertensive effect and achieve rapid BP control [40]. Fixeddose single pills have multiple benefits, including maximizing reduction of $\mathrm{BP}$, minimizing adverse effects, increasing compliance, and preventing CVD and target organ damage [40].

\section{Selection of drugs}

It is reasonable to choose drugs according to the patient's comorbidities and clinical characteristics rather than his or her BP level. There are five available classes of first-line drugs with proven BP-lowering effects, safety, and acceptable adverse effects according to multiple studies. They are: 1) ACE inhibitors or ARBs, 2) beta-blockers, 3) calcium antagonists, 4) diuretics such as hydrochlorothiazide, chlorthalidone, or indapamide, and 5) other drugs (loop diuretics, aldosterone antagonists, alpha-blockers, and direct vasodilators). All reduce BP to a similar extent when the dose has been adjusted. However, there might be individual differences in BP lowering, adverse effects, and long-term CV events, making it very important to choose the appropriate drugs according to the patient's combined risk factors and comorbidities (Table 5). No antihypertensive drug is inherently superior, and the drugs most appropriate for the individual patient should be preferred (Table 5).

\section{Classes of antihypertensive drugs \\ Diuretics}

Diuretics decrease BP initially by reducing reabsorption of sodium in the renal distal convoluted tubules and later by decreasing peripheral vascular resistance. Highdose thiazide-derivative diuretics can induce hypokalemia, glucose intolerance, hyperuricemia, arrhythmia, and adverse lipid metabolism, but low doses rarely have these effects. For decreasing BP, the dose can be increased to $25 \mathrm{mg}$ a day. Combination of diuretics with beta-blockers is not recommended in patients with obesity or high risk for diabetes because of adverse effects such as new-onset diabetes and adverse lipid metabolism. No specific thiazide diuretic is recommended over the others because there has been no study comparing them directly, although chlorthalidone and indapamide are reported to be most effective for lowering BP [67]. As thiazide diuretics must frequently be administered at high doses to achieve optimal BP control, and because such high doses increase the adverse effects, thiazidelike diuretics may be preferred to avoid high dosage and/or reduce metabolic derangement. Spironolactone is proven effective in patients with heart failure and can also be considered at low doses (range, 20 to $50 \mathrm{mg}$ ) for treatment of resistant HTN.

\section{Beta-blockers}

Selective beta-1 blockers are recommended for patients with HTN in combination with angina pectoris, myocardial infarction, or tachycardia. Beta-blockers are also effective in younger patients who have higher heart rates [40]. 
Table 4 Compelling indications for choosing the antihypertensive drugs $[40,66]$

\begin{tabular}{|c|c|c|c|c|}
\hline & $\begin{array}{l}\text { Angiotensin-converting enzyme } \\
\text { inhibitors/angiotensin receptor blockers }\end{array}$ & Beta-blockers & Calcium antagonists & Diuretics \\
\hline Congestive heart failure & $\mathrm{O}$ & $\mathrm{O}$ & & $\mathrm{O}$ \\
\hline Left ventricular hypertrophy & O & & O & \\
\hline Coronary artery disease & $\mathrm{O}$ & $\mathrm{O}$ & & \\
\hline Diabetic nephropathy & $\mathrm{O}$ & & & \\
\hline Stroke & O & & O & $\mathrm{O}$ \\
\hline Elderly, isolated systolic hypertension & $\mathrm{O}$ & & $\mathrm{O}$ & $\mathrm{O}$ \\
\hline Post-myocardial infarction & $\mathrm{O}$ & $\mathrm{O}$ & & \\
\hline Prevention of atrial fibrillation & $\mathrm{O}$ & & & \\
\hline Diabetes & $\mathrm{O}$ & & & \\
\hline
\end{tabular}

However, they should be used with caution in patients with asthma, chronic obstructive pulmonary disease, second- or third-degree atrioventricular block, or peripheral vascular disease [40].

Beta-blockers can have adverse effects on blood glucose and lipid metabolism and should therefore be used cautiously in elderly patients or patients with elevated blood sugar, diabetes, or metabolic syndrome [68]. They should also be used carefully in patients with variant angina because they can worsen symptoms. [69] Because atenolol is inferior for stroke prevention, first-line therapy is not recommended for elderly patients with HTN [70]. Concomitant use of beta-blockers and diuretics will increase the incidence of diabetes and should therefore be avoided in patients at high risk for developing diabetes [68]. Vasodilatory beta-blockers might have different effects than atenolol, but no comparative study has yet been performed $[71,72]$.

\section{Calcium antagonists}

Long-acting calcium antagonists are preferable to shortacting calcium antagonists, which can cause tachycardia and increase cardiac workload. Because calcium antagonists have a vasodilatory effect on the coronary artery, they are highly effective in patients with stable angina or variant angina, which is caused by coronary artery spasm. They are also effective for slowing the progression of carotid atherosclerosis and reducing cardiac hypertrophy [73]. The nondihydropyridine calcium antagonists, verapamil and diltiazem, are effective after myocardial infarction because they do not produce reflex tachycardia. They are also effective in patients with hypertrophic cardiomyopathy because they improve diastolic filling. The common side effects of dihydropyridine calcium antagonists are tachycardia, ankle edema, headache, and facial flushing. Non-dihydropyridine calcium antagonists may cause constipation, conduction delay, and decreased myocardial contractility and should therefore be prescribed cautiously to patients with systolic heart failure or heart block. In addition, special caution is needed when administering them in combination with beta-blockers in elderly patients.

\section{Angiotensin-converting enzyme inhibitors/angiotensin receptor blockers}

ACE inhibitors/angiotensin receptor blockers reduce mortality in patients with heart failure and help to inhibit the progression of renal disease. They also help to prevent LVH and atherosclerosis but have little effect on blood glucose or lipid metabolism [74]. In addition, they can improve vascular endothelial cell function and

Table 5 Indications and contraindications of antihypertensive drugs

\begin{tabular}{|c|c|c|c|c|}
\hline & Absolute indications & $\begin{array}{l}\text { Relative } \\
\text { indications }\end{array}$ & Need cautions & $\begin{array}{l}\text { Absolute } \\
\text { contraindications }\end{array}$ \\
\hline $\begin{array}{l}\text { Angiotensin-converting enzyme } \\
\text { inhibitors/angiotensin receptor } \\
\text { blockers }\end{array}$ & CHF, diabetic nephropathy & & $\begin{array}{l}\text { Renal artery } \\
\text { stenosis, } \\
\text { hyperkalemia }\end{array}$ & $\begin{array}{l}\text { Pregnancy, } \\
\text { angioedema }\end{array}$ \\
\hline Beta-blockers & Ischemic heart disease, myocardial infarction & Tachyarrhythmia & $\begin{array}{l}\text { High blood } \\
\text { glucose, peripheral } \\
\text { artery disease }\end{array}$ & $\begin{array}{l}\text { Asthma, severe and } \\
\text { symptomatic } \\
\text { bradyarrhythmia }\end{array}$ \\
\hline Calcium antagonists & $\begin{array}{l}\text { Elderly hypertension, isolate systolic hypertension, } \\
\text { ischemic heart disease (non-dihydropyridine } \\
\text { calcium antagonists) }\end{array}$ & & $\mathrm{CHF}$ & $\begin{array}{l}\text { Severe and } \\
\text { symptomatic } \\
\text { bradyarrhythmia }\end{array}$ \\
\hline Diuretics & CHF, isolated systolic hypertension & & High blood glucose & Gout hypokalemia \\
\hline
\end{tabular}

CHF congestive heart failure. 
promote revascularization. However, they can cause a hypotensive response in dehydrated or elderly patients [75]. When administered to a patient with bilateral renal artery stenosis, they can have adverse effects such as severe hypotension and deterioration of renal function [75]. The serum creatinine level may increase within the first 2 months after the start of treatment. However, there is no need to discontinue the drug unless the serum creatinine increases to less than $30 \%$ rise than the baseline creatinine level or unless serum potassium is $5.5 \mathrm{mEq} / \mathrm{L}$ or higher [76]. Care should be taken in patients with a serum creatinine level higher than $3.0 \mathrm{mg} /$ $\mathrm{dL}$ [77]. The blood potassium level and renal function should be checked before and within 1 to 2 weeks after administration of the drug and then again 3 or 6 months later. ACE inhibitors inhibit bradykinin degradation and can thus cause a dry cough, but this resolves within a few days to a few weeks after stopping the medication. Dry cough is more common in women and nonsmokers. Angiotensin receptor blockers have no effect on bradykinin and therefore rarely cause cough. ACE inhibitors/ angiotensin receptor blockers are contraindicated in pregnant women because of their teratogenic effects on the fetus.

\section{Others}

Alpha-blockers can alleviate urinary symptoms in patients with prostate enlargement and also improve the metabolism of sugars and lipids. However, they can cause orthostatic hypotension and are associated with worsening of heart failure. Agents that act on the central nervous system, such as clonidine, methyldopa, and reserpine, have many side effects and are therefore not recommended as first-line drugs. Renin inhibitors have been developed and used in other countries but have not yet been introduced in Korea. Renin inhibitors significantly reduced BP and proteinuria when used alone or in combination with diuretics. However, aliskiren has not been proven to improve the prognosis of patients with CVD. Methyldopa is still preferred for the treatment of HTN in pregnant women but is not the first choice because of its side effects. Hydralazine is a vasodilator that is relatively safe for pregnant women with HTN.

\section{Combination therapy}

More than 2/3 of patients with HTN need drugs from more than two drug classes with different mechanisms to achieve control of HTN. Combination therapy is particularly helpful for patients receiving prolonged BP treatment, high-risk patients, and patients with a low target BP. If the first drug used is not effective for BP control, then a drug of another class should be tried. If the efficacy is insufficient, the dose should be increased or another drug added. However, it is recommended to combine two different drugs in smaller doses rather than to increase the dosage of one drug because such lowdose combinations lower BP more effectively and improve the compliance while decreasing the adverse effects (Figure 2) [78].

If $\mathrm{BP}$ is not controlled with a single drug, two drugs should be combined for BP control. Combination therapy is more effective than single-drug therapy at a higher dose [78]. However, it has not been fully evaluated which combination is best. Combination therapy chosen from the renin-angiotensin system inhibitors, calcium antagonists,

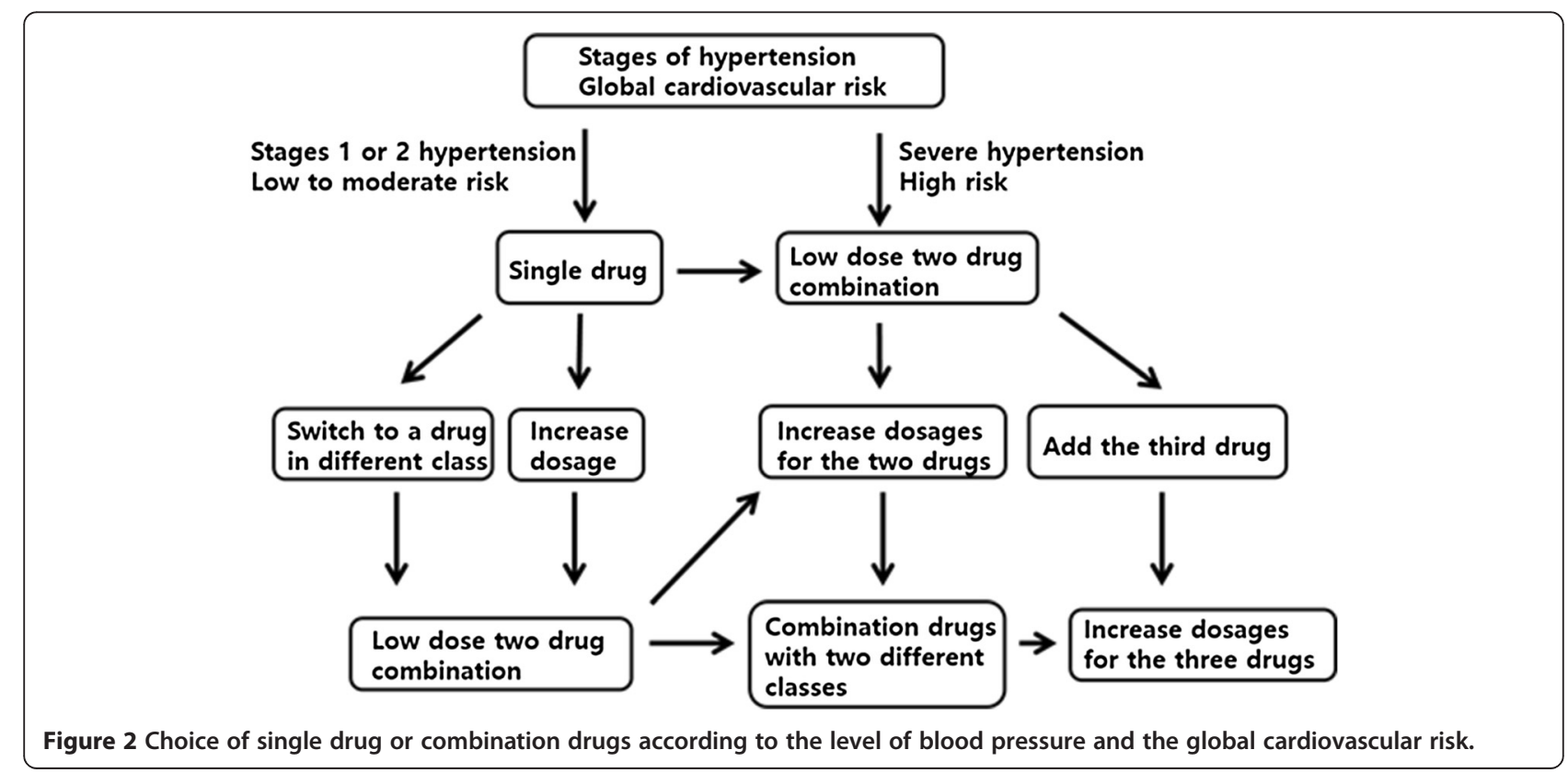


and diuretics is recommended first because it has shown relatively good results $[17,79,80]$, but beta-blockers can also be combined with drugs of other classes (Figure 3). However, the combination of beta-blockers and diuretics can increase the incidence of diabetes and metabolic disorders and thus requires periodic monitoring. Combination therapy with angiotensin-receptor blockers and ACE inhibitors may be slightly more effective for reducing proteinuria but increases the risk for end-stage renal failure, stroke, and other CVD [81-83].

\section{Resistant hypertension}

Resistant HTN is defined as BP that cannot be controlled $(\mathrm{BP} \geq 140 / 90 \mathrm{~mm} \mathrm{Hg})$ despite treatment with more than three different classes of antihypertensive drugs, including diuretics. The prevalence of resistant HTN is reported to be $5 \%$ to $30 \%$ in other countries. However, considering the frequency of pseudo-resistant HTN, the prevalence of true resistant HTN is assumed to be less than $10 \%$ [40]. Patients with resistant HTN are at much higher risk for complications such as CVD and kidney disease [84].

Among the wide range of causes of resistant HTN (Table 6), noncompliance is the most common. In addition, medications taken for relief of cold symptoms, nonsteroidal anti-inflammatory drugs, adrenal cortical steroids, birth control pills, excessive salt intake, and excessive alcohol consumption can also cause resistant HTN. If diuretics have not been included in the regimen, volume overload can cause resistant HTN. Finally, secondary HTN can cause resistant HTN. To diagnose resistant HTN, treatment compliance should be confirmed and then the home BP or ambulatory BP checked in order to exclude white coat HTN. If BP cannot be controlled despite the use of effective doses of three different classes of drug, then the dose of diuretics should be increased, or amiloride added, or thiazide diuretics

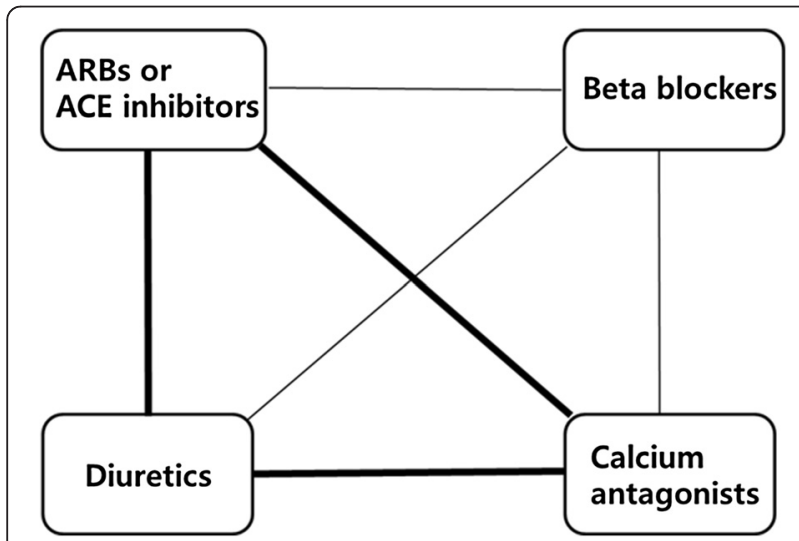

Figure 3 Recommended combination therapy, thick lines; preferred combination, thin line; feasible combination. $A R B$ angiotensin receptor blocker, $A C E$ angiotensin-converting enzyme.
Table 6 Differential diagnosis of uncontrolled hypertension

\begin{tabular}{ll}
\hline Diagnoses & Causes \\
\hline $\begin{array}{ll}\text { Pseudo-resistant } \\
\text { hypertension }\end{array}$ & Poor compliance \\
& Wrong cuff use \\
& Using too small cuff \\
& White coat hypertension \\
& Calcified vessel in the elderly (pseudohypertension)
\end{tabular}

Resistant hypertension

Lifestyle factors: severe weight gain, heavy or binge drinking, excess salt intake

Medication: cold remedies, nonsteroidal anti-inflammatory drugs, corticosteroid, cyclosporine/tacrolimus, erythropoietin, cocaine, herbal licorice

Secondary hypertension

Sleep apnea syndrome

Volume expansion by renal diseases

Vascular damage or stiffness

Prescription of antihypertensive drugs: insufficient dose, wrong use of diuretics, ineffective combination, drug interaction

changed to loop diuretics in patients with renal impairment. However, most patients with resistant HTN require a different mechanism for BP control, and the fourth drug added should be spironolactone or an alphablocker such as doxazosin [85-88].

\section{Renal denervation}

Bilateral destruction of the renal sympathetic nerves that course along the renal artery by the use of radiofrequency ablation catheters is an increasingly popular nondrug therapeutic approach to HTN. Reduction of BP lasts for more than a year after the procedure, and the BP-reducing effect was reported to be maintained for another 3 years of follow-up [89].

The treatment itself has no significant complications and can therefore be used in patients with resistant HTN. However, there is insufficient short-term and long-term evidence for the efficacy of renal denervation [90]. Carotid stimulation is also reported to be effective for lowering BP in patients with resistant HTN; however, there is very little randomized blind study data supporting its efficacy [91].

\section{Reduction or discontinuation of antihypertensive medications}

In patients whose BP has been well controlled for years, the dose of antihypertensive drug can be reduced. Afterwards, the BP should be checked regularly, and the continued practice of lifestyle modifications monitored [40]. 


\section{Other drug treatments}

The goal of antihypertensive therapy is to reduce the overall $\mathrm{CV}$ risk in patients who have other risk factors such as diabetes, dyslipidemia, coronary artery disease, stroke, and CKD. Accordingly, these other risk factors should be treated at the same time.

\section{Antiplatelet therapy}

Aspirin administration was shown to produce an absolute benefit for the secondary prevention of CVD in patients with HTN [92]. However, the role of aspirin for secondary prevention remains a matter of debate.

Low-dose aspirin $(100 \mathrm{mg})$ can be prescribed to patients in high-risk groups in order to reduce the risk of CVD $[92,93]$. Antiplatelet agents should be administered after the BP is controlled, and patients should be checked periodically for gastrointestinal bleeding.

\section{Lipid-lowering agents}

Lipid-lowering agents have a protective effect on highrisk patients with HTN. Although there is very little Korean data, a 50\% reduction in low-density lipoprotein (LDL) cholesterol in patients who had an LDL cholesterol level $\geq 130 \mathrm{mg} / \mathrm{dL}$ significantly lowered the risk for CVD [94]. Lowering the LDL cholesterol level to $<100 \mathrm{mg} / \mathrm{dL}$ is recommended in hypertension patients with coronary artery disease or diabetes mellitus [95]. For hypertension patients with acute coronary syndrome, LDL should be lowered below $70 \mathrm{mg} / \mathrm{dL}$. There is evidence for reducing the LDL cholesterol level to $<135 \mathrm{mg} / \mathrm{dL}$ in patients with stroke [96]; however, there is little data regarding the effect of lowering the LDL cholesterol to $<70 \mathrm{mg} / \mathrm{dL}$ in such patients.

\section{Glycemic control}

Recent clinical studies have shown that aggressive blood glucose control (a hemoglobin A1C level less than $6.0 \%$ or 6.5\%) reduces the incidence of ischemic heart disease in patients with type 2 diabetes; however, there was no significant change or even increase in stroke or total mortality. Therefore, in patients with diabetes, the blood glucose level should be controlled so that the hemoglobin A1C is less than $7.0 \%$ in most patients and less aggressively (target hemoglobin $\mathrm{A} 1 \mathrm{C}$ of $7.5 \%$ to $8.0 \%$ ) in older patients or patients with diabetes of long duration, who have increased risk for hypoglycemia [97].

\section{Monitoring and follow-up}

Patients should generally be followed up once monthly, at least until the target BP is achieved. Patients with severe HTN (stage two or more) need more frequent follow-up. The serum potassium and creatinine levels should be measured at least one to two times yearly. If the BP is controlled and stable, then the patient should be followed up every 3 to 6 months. A longer follow-up interval may be associated with low compliance. Therefore, patient compliance also must be monitored, and the need for blood tests should be emphasized to encourage attendance at follow-up visits. A longer followup interval to monitor the status of BP control can be achieved by encouraging home BP measurement.

\section{Compliance}

Trust between doctor and patient is the most important issue in the treatment of HTN, and the patient should therefore be encouraged to participate in the development of the treatment plan. Many patients may have obtained information about various antihypertensive agents through various routes, so discussion may be necessary. First, identify the patient's point of view to determine the relative importance of efficacy, cost-effectiveness, and side effects. It is necessary to reduce overall $\mathrm{CV}$ risk as much as possible while maintaining the patient's compliance. Self-measurement of BP by using home BP monitoring can improve compliance.

\section{Abbreviations}

ACE: Angiotensin-converting enzyme; ARB: Angiotensin receptor blocker; BMl: Body mass index; BP: Blood pressure; CKD: Chronic kidney disease; CV: Cardiovascular; CVD: Cardiovascular diseases; DBP: Diastolic blood pressure; DM: Diabetes mellitus; HDL: High-density lipoprotein; HTN: Hypertension; KNHANES: Korean National Health and Nutrition Examination Survey; LDL: Low-density lipoprotein; LVH: Left ventricular hypertrophy; SBP: Systolic blood pressure.

\section{Competing interests}

Preparation of this guideline is financially supported by the Korean Society of Hypertension. The authors declare that they have no competing interests.

\section{Acknowledgements}

On behalf of the committee of the clinical practice guidelines at the Korean Society of Hypertension, we thank professors Cheol-Ho Kim and Hyeon Chang Kim for their kind consultations. Additionally, we thank the officials of the The Korean Society of Internal Medicine, The Korean Geriatrics Society, The Korean Stroke Society, The Korean Diabetes Association, The Korean Society of Nephrology, and The Korean Society of Cardiology for their endorsement of this guideline.

\section{Author details}

'Department of Internal Medicine, Hanyang University College of Medicine, Seoul, Korea. ${ }^{2}$ Division of Cardiology, Department of Medicine, Cheil General Hospital, Kwandong University College of Medicine, Seoul, Korea. ${ }^{3}$ Department of Internal Medicine, School of Medicine, Seoul National University, Bundang, Korea. ${ }^{4}$ Department of Internal Medicine, School of Medicine, Chonnam University, Gwangju, Korea. ${ }^{5}$ Division of Cardiology, Department of Internal Medicine, Kyungpook National University School of Medicine, 130 Dongdeok-ro, 700-721 Jung-gu, Daegu, Korea. ${ }^{6}$ Division of Cardiology, Department of Internal Medicine, Ewha Womans University School of Medicine, Seoul, Korea. ${ }^{7}$ Division of Cardiology, Department of Internal Medicine, Dongkuk University School of Medicine, Seoul, Korea.

Received: 2 December 2014 Accepted: 23 December 2014 Published online: 08 April 2015

\section{References}

1. Lewington S, Clarke R, Qizilbash N, Peto R, Prospective CR, Studies C. Agespecific relevance of usual blood pressure to vascular mortality: a metaanalysis of individual data for one million adults in 61 prospective studies. Lancet. 2002;360:1903-13. 
2. Julius S, Nesbitt SD, Egan BM, Weber MA, Michelson EL, Kaciroti N, et al. Feasibility of treating prehypertension with an angiotensin-receptor blocker. N Engl J Med. 2006;354:1685-97.

3. Hamada T, Murata T, Narita K, Takahashi T, Wada Y, Kimura H, et al. The clinical significance of abnormal diurnal blood pressure variation in healthy late middle-aged and older adults. Blood Press. 2008;17:134-40.

4. Luders S, Schrader J, Berger J, Unger T, Zidek W, Bohm M, et al. The PHARAO study: prevention of hypertension with the angiotensin-converting enzyme inhibitor ramipril in patients with high-normal blood pressure: a prospective, randomized, controlled prevention trial of the German Hypertension League. J Hypertens. 2008;26:1487-96.

5. Zanchetti A, Grassi G, Mancia G. When should antihypertensive drug treatment be initiated and to what levels should systolic blood pressure be lowered? A critical reappraisal. J Hypertens. 2009:27:923-34.

6. Dagenais GR, Gerstein HC, Holman R, Budaj A, Escalante A, Hedner T, et al. Effects of ramipril and rosiglitazone on cardiovascular and renal outcomes in people with impaired glucose tolerance or impaired fasting glucose: results of the Diabetes REduction Assessment with ramipril and rosiglitazone Medication (DREAM) trial. Diabetes Care. 2008;31:1007-14.

7. McMurray JJ, Holman RR, Haffner SM, Bethel MA, Holzhauer B, Hua TA, et al. Effect of valsartan on the incidence of diabetes and cardiovascular events. N Engl J Med. 2010;362:1477-90.

8. Schrier RW, Estacio RO, Esler A, Mehler P. Effects of aggressive blood pressure control in normotensive type 2 diabetic patients on albuminuria, retinopathy and strokes. Kidney Int. 2002;61:1086-97.

9. Arima H, Chalmers J, Woodward M, Anderson C, Rodgers A, Davis S, et al. Lower target blood pressures are safe and effective for the prevention of recurrent stroke: the PROGRESS trial. J Hypertens. 2006;24:1201-8.

10. Zanchetti A, Amery A, Berglund G, Cruickshank JM, Hansson L, Lever AF, et al. How much should blood pressure be lowered? The problem of the J-shaped curve. J Hypertens Suppl. 1989;7:S338-48.

11. Zanchetti A. Bottom blood pressure or bottom cardiovascular risk? How far can cardiovascular risk be reduced? J Hypertens. 2009;27:1509-20.

12. MRC trial of treatment of mild hypertension: principal results. Medical Research Council Working Party. Br Med J (Clin Res Ed). 1985;291:97-104.

13. The Australian therapeutic trial in mild hypertension. Report by the Management Committee. Lancet. 1980;1:1261-7.

14. Collins R, MacMahon S. Blood pressure, antihypertensive drug treatment and the risks of stroke and of coronary heart disease. Br Med Bull. 1994:50:272-98.

15. Law MR, Morris JK, Wald NJ. Use of blood pressure lowering drugs in the prevention of cardiovascular disease: meta-analysis of 147 randomised trials in the context of expectations from prospective epidemiological studies. BMJ. 2009;338:b1665.

16. Aronow WS, Fleg JL, Pepine CJ, Artinian NT, Bakris G, Brown AS, et al. ACCF/ AHA 2011 expert consensus document on hypertension in the elderly: a report of the American College of Cardiology Foundation Task Force on Clinical Expert Consensus documents developed in collaboration with the American Academy of Neurology, American Geriatrics Society, American Society for Preventive Cardiology, American Society of Hypertension, American Society of Nephrology, Association of Black Cardiologists, and European Society of Hypertension. J Am Coll Cardiol. 2011;57:2037-114.

17. Liu L, Zhang Y, Liu G, Li W, Zhang X, Zanchetti A, et al. The Felodipine Event Reduction (FEVER) study: a randomized long-term placebo-controlled trial in Chinese hypertensive patients. J Hypertens. 2005;23:2157-72.

18. Zhang $Y$, Zhang $X$, Liu L, Zanchetti A, Group FS. Is a systolic blood pressure target $<140 \mathrm{mmHg}$ indicated in all hypertensives? Subgroup analyses of findings from the randomized FEVER trial. Eur Heart J. 2011;32:1500-8.

19. Beckett NS, Peters R, Fletcher AE, Staessen JA, Liu L, Dumitrascu D, et al. Treatment of hypertension in patients 80 years of age or older. N Engl J Med. 2008;358:1887-98.

20. JATOS Study Group. Principal results of the Japanese trial to assess optimal systolic blood pressure in elderly hypertensive patients (JATOS). Hypertens Res. 2008;31:2115-27.

21. Ogihara T, Saruta T, Rakugi H, Matsuoka H, Shimamoto K, Shimada K, et al. Target blood pressure for treatment of isolated systolic hypertension in the elderly: valsartan in elderly isolated systolic hypertension study. Hypertension. 2010;56:196-202.

22. Reboldi G, Gentile G, Angeli F, Ambrosio G, Mancia G, Verdecchia P. Effects of intensive blood pressure reduction on myocardial infarction and stroke in diabetes: a meta-analysis in 73,913 patients. J Hypertens. 2011;29:1253-69.
23. Cushman WC, Evans GW, Byington RP, Goff Jr DC, Grimm Jr RH, Cutler JA, et al. Effects of intensive blood-pressure control in type 2 diabetes mellitus. N Engl J Med. 2010;362:1575-85.

24. Hansson L, Zanchetti A, Carruthers SG, Dahlof B, Elmfeldt D, Julius S, et al. Effects of intensive blood-pressure lowering and low-dose aspirin in patients with hypertension: principal results of the hypertension optimal treatment (HOT) randomised trial. HOT Study Group. Lancet. 1998;351:1755-62.

25. PATS Collaborating Group. Poststroke antihypertensive treatment study. A preliminary result. Chin Med J (Engl). 1995;108:8.

26. Progress Collaborative Group. Randomised trial of a perindopril-based blood-pressure-lowering regimen among 6,105 individuals with previous stroke or transient ischaemic attack. Lancet. 2001;358:1033-41.

27. Rashid P, Leonardi-Bee J, Bath P. Blood pressure reduction and secondary prevention of stroke and other vascular events: a systematic review. Stroke. 2003;34:2741-8.

28. Ovbiagele B, Diener HC, Yusuf S, Martin RH, Cotton D, Vinisko R, et al. Level of systolic blood pressure within the normal range and risk of recurrent stroke. JAMA. 2011;306:2137-44

29. Yusuf S, Diener HC, Sacco RL, Cotton D, Ounpuu S, Lawton WA, et al. Telmisartan to prevent recurrent stroke and cardiovascular events. N Engl J Med. 2008;359:1225-37.

30. Fox KM. EURopean trial On reduction of cardiac events with Perindopril in stable coronary Artery disease Investigators. Efficacy of perindopril in reduction of cardiovascular events among patients with stable coronary artery disease: randomised, double-blind, placebo-controlled, multicentre trial (the EUROPA study). Lancet. 2003;362:782-8.

31. Poole-Wilson PA, Lubsen J, Kirwan BA, Van Dalen FJ, Wagener G, Danchin N, et al. Effect of long-acting nifedipine on mortality and cardiovascular morbidity in patients with stable angina requiring treatment (ACTION trial): randomised controlled trial. Lancet. 2004;364:849-57.

32. Braunwald E, Domanski MJ, Fowler SE, Geller NL, Gersh BJ, Hsia J, et al. Angiotensin-converting-enzyme inhibition in stable coronary artery disease. N Engl J Med. 2004;351:2058-68.

33. Klahr S, Levey AS, Beck GJ, Caggiula AW, Hunsicker L, Kusek JW, et al. The effects of dietary protein restriction and blood-pressure control on the progression of chronic renal disease. Modification of Diet in Renal Disease Study Group. N Engl J Med. 1994;330:877-84.

34. Wright Jr JT, Bakris G, Greene T, Agodoa LY, Appel LJ, Charleston J, et al. Effect of blood pressure lowering and antihypertensive drug class on progression of hypertensive kidney disease: results from the AASK trial. JAMA. 2002;288:2421-31.

35. Ruggenenti P, Perna A, Loriga G, Ganeva M, Ene-lordache B, Turturro M, et al. Blood-pressure control for renoprotection in patients with nondiabetic chronic renal disease (REIN-2): multicentre, randomised controlled trial. Lancet. 2005;365:939-46.

36. Sarnak MJ, Greene T, Wang X, Beck G, Kusek JW, Collins AJ, et al. The effect of a lower target blood pressure on the progression of kidney disease: long-term follow-up of the modification of diet in renal disease study. Ann Intern Med. 2005;142:342-51.

37. Appel LJ, Wright Jr JT, Greene T, Agodoa LY, Astor BC, Bakris GL, et al. Intensive blood-pressure control in hypertensive chronic kidney disease. N Engl J Med. 2010;363:918-29.

38. Arguedas JA, Perez MI, Wright JM. Treatment blood pressure targets for hypertension. Cochrane Database Syst Rev. 2009;8(3):CD004349. doi:10.1002/14651858.

39. Upadhyay A, Earley A, Haynes SM, Uhlig K. Systematic review: blood pressure target in chronic kidney disease and proteinuria as an effect modifier. Ann Intern Med. 2011;154:541-8.

40. Mancia G, Fagard R, Narkiewicz K, Redon J, Zanchetti A, Bohm M, et al. 2013 ESH/ESC Guidelines for the management of arterial hypertension: the Task Force for the management of arterial hypertension of the European Society of Hypertension (ESH) and of the European Society of Cardiology (ESC). J Hypertens. 2013;31:1281-357.

41. Messerli FH, Kupfer S, Pepine CJ. J curve in hypertension and coronary artery disease. Am J Cardiol. 2005;95:160.

42. Elmer PJ, Obarzanek E, Vollmer WM, Simons-Morton D, Stevens VJ, Young DR, et al. Effects of comprehensive lifestyle modification on diet, weight, physical fitness, and blood pressure control: 18-month results of a randomized trial. Ann Intern Med. 2006;144:485-95.

43. 2010 Korean National Health Statistics. 2010 Korean National Health and Nutrition Examination Survey. 2010. 
44. Park S, Park JB, Lakatta EG. Association of central hemodynamics with estimated 24-h urinary sodium in patients with hypertension. J Hypertens. 2011;29:1502-7.

45. He FJ, MacGregor GA. How far should salt intake be reduced? Hypertension. 2003:42:1093-9.

46. Graudal NA, Hubeck-Graudal T, Jurgens G. Effects of low-sodium diet vs. highsodium diet on blood pressure, renin, aldosterone, catecholamines, cholesterol, and triglyceride (Cochrane review). Am J Hypertens. 2012;25:1-15.

47. He FJ, Burnier M, Macgregor GA. Nutrition in cardiovascular disease: salt in hypertension and heart failure. Eur Heart J. 2011;32:3073-80.

48. Bibbins-Domingo K, Chertow GM, Coxson PG, Moran A, Lightwood JM, Pletcher MJ, et al. Projected effect of dietary salt reductions on future cardiovascular disease. N Engl J Med. 2010;362:590-9.

49. He FJ, MacGregor GA. Salt reduction lowers cardiovascular risk: metaanalysis of outcome trials. Lancet. 2011;378:380-2.

50. Taylor RS, Ashton KE, Moxham T, Hooper L, Ebrahim S. Reduced dietary salt for the prevention of cardiovascular disease: a meta-analysis of randomized controlled trials (Cochrane review). Am J Hypertens. 2011;24:843-53.

51. O'Donnell MJ, Mente A, Smyth A, Yusuf S. Salt intake and cardiovascular disease: why are the data inconsistent? Eur Heart J. 2013;34:1034-40.

52. Whitlock G, Lewington S, Sherliker P, Clarke R, Emberson J, Halsey J, et al. Body-mass index and cause-specific mortality in 900000 adults: collaborative analyses of 57 prospective studies. Lancet. 2009;373:1083-96.

53. Flegal KM, Kit BK, Orpana H, Graubard BI. Association of all-cause mortality with overweight and obesity using standard body mass index categories: a systematic review and meta-analysis. JAMA. 2013;309:71-82.

54. Jee SH, Sull JW, Park J, Lee SY, Ohrr H, Guallar E, et al. Body-mass index and mortality in Korean men and women. N Engl J Med. 2006;355:779-87.

55. International Association for the Study of Obesity. The Asia-Pacific Perspective: redefining obesity and its treatment.: West Pacific Region WHO. 2000.

56. Cornelissen VA, Fagard RH, Coeckelberghs E, Vanhees L. Impact of resistance training on blood pressure and other cardiovascular risk factors: a metaanalysis of randomized, controlled trials. Hypertension. 2011;58:950-8.

57. Mann SJ, James GD, Wang RS, Pickering TG. Elevation of ambulatory systolic blood pressure in hypertensive smokers. A case-control study. JAMA. 1991;265:2226-8.

58. Doll R, Peto R, Wheatley K, Gray R, Sutherland I. Mortality in relation to smoking: 40 years' observations on male British doctors. BMJ. 1994;309:901-11.

59. Appel LJ, Moore TJ, Obarzanek E, Vollmer WM, Svetkey LP, Sacks FM, et al. A clinical trial of the effects of dietary patterns on blood pressure, DASH Collaborative Research Group. N Engl J Med. 1997;336:1117-24.

60. Obarzanek E, Sacks FM, Vollmer WM, Bray GA, Miller 3rd ER, Lin PH, et al. Effects on blood lipids of a blood pressure-lowering diet: the Dietary Approaches to Stop Hypertension (DASH) Trial. Am J Clin Nutr. 2001;74:80-9.

61. Sacks FM, Appel $\sqcup$, Moore TJ, Obarzanek E, Vollmer WM, Svetkey LP, et al. A dietary approach to prevent hypertension: a review of the Dietary Approaches to Stop Hypertension (DASH) Study. Clin Cardiol. 1999;22:III6-III10.

62. Svetkey LP, Simons-Morton D, Vollmer WM, Appel LJ, Conlin PR, Ryan DH, et al. Effects of dietary patterns on blood pressure: subgroup analysis of the Dietary Approaches to Stop Hypertension (DASH) randomized clinical trial. Arch Intern Med. 1999;159:285-93.

63. Estruch R, Ros E, Salas-Salvado J, Covas MI, Corella D, Aros F, et al. Primary prevention of cardiovascular disease with a Mediterranean diet. N Engl J Med. 2013;368:1279-90.

64. Martell N, Gill B, Marin R, Suarez C, Tovar JL, Cia P, et al. Trough to peak ratio of once-daily lisinopril and twice-daily captopril in patients with essential hypertension. J Hum Hypertens. 1998;12:69-72.

65. Lipicky RJ. Trough: peak ratio: the rationale behind the United States Food and Drug Administration recommendations. J Hypertens. 1994;12:S17-8. discussion S8-9.

66. Chobanian AV, Bakris GL, Black HR, Cushman WC, Green LA, Izzo Jr JL, et al, Seventh report of the Joint National Committee on Prevention, Detection, Evaluation, and Treatment of High Blood Pressure. Hypertension. 2003;42:1206-52.

67. National Institute for Health and Clinical Excellence. Hypertension (CG127): clinical management of primary hypertension in adults. http://wwwniceorguk/ guidance/CG127.

68. Elliott WJ, Meyer PM. Incident diabetes in clinical trials of antihypertensive drugs: a network meta-analysis. Lancet. 2007;369:201-7.

69. Keller KB, Lemberg L. Prinzmetal's angina. Am J Crit Care. 2004;13:350-4.
70. Campbell NR, Poirier L, Tremblay G, Lindsay P, Reid D, Tobe SW, et al. Canadian Hypertension Education Program: the science supporting New 2011 CHEP recommendations with an emphasis on health advocacy and knowledge translation. Can J Cardiol. 2011;27:407-14.

71. Bakris GL, Fonseca V, Katholi RE, McGill JB, Messerli FH, Phillips RA, et al. Metabolic effects of carvedilol vs metoprolol in patients with type 2 diabetes mellitus and hypertension: a randomized controlled trial. JAMA. 2004;292:2227-36.

72. Celik T, Iyisoy A, Kursaklioglu H, Kardesoglu E, Kilic S, Turhan H, et al. Comparative effects of nebivolol and metoprolol on oxidative stress, insulin resistance, plasma adiponectin and soluble P-selectin levels in hypertensive patients. J Hypertens. 2006;24:591-6.

73. Zanchetti A, Bond MG, Hennig M, Neiss A, Mancia G, Dal Palu C, et al. Calcium antagonist lacidipine slows down progression of asymptomatic carotid atherosclerosis: principal results of the European Lacidipine Study on Atherosclerosis (ELSA), a randomized, double-blind, long-term trial. Circulation. 2002;106:2422-7.

74. Mancia G, Laurent S, Agabiti-Rosei E, Ambrosioni E, Burnier M, Caulfield MJ, et al. Reappraisal of European guidelines on hypertension management: a European Society of Hypertension Task Force document. J Hypertens. 2009;27:2121-58.

75. Brown NJ, Vaughan DE. Angiotensin-converting enzyme inhibitors. Circulation. 1998;97:1411-20

76. Palmer BF. Managing hyperkalemia caused by inhibitors of the reninangiotensin-aldosterone system. N Engl J Med. 2004;351:585-92.

77. Bicket DP. Using ACE, inhibitors appropriately. Am Fam Physician. 2002;66:461-8.

78. Wald DS, Law M, Morris JK, Bestwick JP, Wald NJ. Combination therapy versus monotherapy in reducing blood pressure: meta-analysis on 11,000 participants from 42 trials. Am J Med. 2009;122:290-300.

79. Patel A, MacMahon S, Chalmers J, Neal B, Woodward M, Billot L, et al. Effects of a fixed combination of perindopril and indapamide on macrovascular and microvascular outcomes in patients with type 2 diabetes mellitus (the ADVANCE trial): a randomised controlled trial. Lancet. 2007;370:829-40.

80. Jamerson K, Weber MA, Bakris GL, Dahlof B, Pitt B, Shi V, et al. Benazepril plus amlodipine or hydrochlorothiazide for hypertension in high-risk patients. N Engl J Med. 2008;359:2417-28.

81. Mann JF, Schmieder RE, McQueen M, Dyal L, Schumacher H, Pogue J, et al. Renal outcomes with telmisartan, ramipril, or both, in people at high vascular risk (the ONTARGET study): a multicentre, randomised, doubleblind, controlled trial. Lancet. 2008;372:547-53.

82. Parving HH, Brenner BM, McMurray JJ, De Zeeuw D, Haffner SM, Solomon $\mathrm{SD}$, et al. Cardiorenal end points in a trial of aliskiren for type 2 diabetes. N Engl J Med. 2012;367:2204-13.

83. Yusuf S, Teo KK, Pogue J, Dyal L, Copland I, Schumacher $\mathrm{H}$, et al. Telmisartan, ramipril, or both in patients at high risk for vascular events. N Engl J Med. 2008;358:1547-59.

84. Persell SD. Prevalence of resistant hypertension in the United States, 2003-2008. Hypertension. 2011;57:1076-80.

85. Zannad F. Aldosterone antagonist therapy in resistant hypertension. J Hypertens. 2007;25:747-50.

86. Chapman N, Chang CL, Dahlof B, Sever PS, Wedel H, Poulter NR, et al. Effect of doxazosin gastrointestinal therapeutic system as third-line antihypertensive therapy on blood pressure and lipids in the Anglo-Scandinavian Cardiac Outcomes Trial. Circulation. 2008;118:42-8.

87. Bobrie G, Frank M, Azizi M, Peyrard S, Boutouyrie P, Chatellier G, et al. Sequential nephron blockade versus sequential renin-angiotensin system blockade in resistant hypertension: a prospective, randomized, open blinded endpoint study. J Hypertens. 2012;30:1656-64.

88. Gaddam KK, Nishizaka MK, Pratt-Ubunama MN, Pimenta E, Aban I, Oparil S, et al. Characterization of resistant hypertension: association between resistant hypertension, aldosterone, and persistent intravascular volume expansion. Arch Intern Med. 2008;168:1159-64.

89. Esler MD, Krum H, Sobotka PA, Schlaich MP, Schmieder RE, Bohm M, et al. Renal sympathetic denervation in patients with treatment-resistant hypertension (The Symplicity HTN-2 Trial): a randomised controlled trial. Lancet. 2010;376:1903-9.

90. Bhatt DL, Kandzari DE, O'Neill WW, D'Agostino R, Flack JM, Katzen BT, et al. A controlled trial of renal denervation for resistant hypertension. N Engl J Med. 2014;370:1393-401.

91. Bisognano JD, Bakris G, Nadim MK, Sanchez L, Kroon AA, Schafer J, et al. Baroreflex activation therapy lowers blood pressure in patients with 
resistant hypertension: results from the double-blind, randomized, placebocontrolled rheos pivotal trial. J Am Coll Cardiol. 2011;58:765-73.

92. Baigent C, Blackwell L, Collins R, Emberson J, Godwin J, Peto R, et al. Aspirin in the primary and secondary prevention of vascular disease: collaborative meta-analysis of individual participant data from randomised trials. Lancet. 2009;373:1849-60.

93. Jardine MJ, Ninomiya T, Perkovic V, Cass A, Turnbull F, Gallagher MP, et al. Aspirin is beneficial in hypertensive patients with chronic kidney disease: a post-hoc subgroup analysis of a randomized controlled trial. J Am Coll Cardiol. 2010;56:956-65.

94. Ridker PM, Danielson E, Fonseca FA, Genest J, Gotto Jr AM, Kastelein JJ, et al. Rosuvastatin to prevent vascular events in men and women with elevated C-reactive protein. N Engl J Med. 2008;359:2195-207.

95. Baigent C, Blackwell L, Emberson J, Holland LE, Reith C, Bhala N, et al. Cholesterol Treatment Trialists, Collaboration. Efficacy and safety of more intensive lowering of LDL cholesterol: a meta-analysis of data from 170,000 participants in 26 randomised trials. Lancet. 2010;376:1670-81.

96. Amarenco P, Bogousslavsky J, Callahan 3rd A, Goldstein LB, Hennerici M, Rudolph $\mathrm{AE}$, et al. High-dose atorvastatin after stroke or transient ischemic attack. N Engl J Med. 2006;355:549-59.

97. Inzucchi SE, Bergenstal RM, Buse JB, Diamant M, Ferrannini E, Nauck M, et al. Management of hyperglycaemia in type 2 diabetes: a patient-centered approach. Position statement of the American Diabetes Association (ADA) and the European Association for the Study of Diabetes (EASD).

Diabetologia. 2012;55:1577-96.

\section{Submit your next manuscript to BioMed Central and take full advantage of:}

- Convenient online submission

- Thorough peer review

- No space constraints or color figure charges

- Immediate publication on acceptance

- Inclusion in PubMed, CAS, Scopus and Google Scholar

- Research which is freely available for redistribution 